\title{
Innovation Potential of the Economy of the Region, the System of Indicators
}

\author{
Ablaev I.M. \\ Kazan Federal University, Institute of Management, Economics and Finance, Kazan, 420008, Russia \\ Email: ildar_ablaev@mail.ru
}

\section{Doi:10.5901/mjss.2015.v6n1s3p309}

\begin{abstract}
The article focuses on the existing approaches to evaluation of the innovation systems, analyzes the set of indicators involved in assessment. The article touches on the current tendencies in the state innovation development, marks their weak points and suggests the perspective ways for further effective development of the innovation system
\end{abstract}

Keywords: innovation potential, innovation systems, innovation assessment methods, systems of indicators, regional economy

\section{Introduction}

In the modern economic literature a great attention is paid to the importance of the efficient use of the innovation potential in terms of the global economic crisis. The significant task is the choice of the most adequate system of the innovation potential assessment that would make possible the precise and competent evaluation of the innovation degree of every region. The statement of this problem is closely related to the fact that the modern economic world faces the imperfection of the existing methods of innovation potential assessment.

\section{Theory}

There is a number of approaches to the innovation system evaluation [6]. In the first place comes the approach suggested by the World Bank in 2004 within the program "Knowledge for Development" (K\&D), it is proved to be one of the most full and complex approach applicable to evaluation of the knowledge-based economy. The devised methodology (The Knowledge Assessment Methodology, KAM) [1] deals with comparison and estimation of the readiness of the countries for transition to a new development model based on knowledge, it uses 76 indicators and several aggregated indices that contribute to the Knowledge Index (KI) and the Knowledge Economy Index (KEI) [2].

The structure of the Knowledge Economy Index makes up of the following indices:

1) "General indices" (such as the annual growth rate of GDP, the Human Development Index (HDI));

2) "Institutional mode of the economic system functioning" that includes: the level of the tariff and non-tariff barriers; the quality of economic regulation (the expert assessment of the price control; regulation of the banking, international trade and business development); the degree of compliance (the expert assessment of the crime rate etc.);

3) "Education and human potential": the literacy level of the adult population; the level of involvement of the population of the corresponding age categories in the secondary and higher education;

4) "Innovation system" (as definite environment): the quantity of the research workers in the sphere of R\&D, the quantity of the lodged and approved patent applications; the quantity of the publications in the scientific and technical journals (all in calculation per million of the total population);

5) "Information infrastructure": the number of fixed and mobile phones, computers per mille; the number of the internet users per mille.

Besides the system of indices suggested by the World Bank it is common to apply the so called "cluster approach" in the analysis of the knowledge flows within the national innovation system, which consists in ascertainment of the close horizontal and vertical interactions between certain firms and industrial sectors united in clusters on the basis of their technological ties, supplies processes, knowledge and skill interchange. This approach was employed in the theory of clusters. First, the basics of the cluster approach were introduced by N.D. Kondratyev in his research of the dynamics of innovations. Kondratyev proved that innovations are spread unevenly, emerging in groups, i.e. clusters. Later J. Schumpeter associated the long periods of imbalance of the economic system that come out in the low-frequency 
fluctuations of the conjuncture and are accompanied by the occasional concentration of the innovations into clusters with their further synchronic distribution. The most significant contribution to the cluster theory was made by the American scientist M.Porter [5]. This theory is based on the notion that the most competitive on the global scale firms of the same industrial sector are usually accumulated in one region, and this is specified by the wave nature of innovations that are spread through the most competitive companies and affect the suppliers, the customers and the competitors of those companies.

The mechanism of the positive impact produced by cluster evidences in the following interrelations:

- the new producers coming from other economic sectors accelerate their development by means of R\&D promotion and provision of the financial support needed for the implementation of the new strategies;

- there is a free information interchange and rapid spread of innovations via the suppliers or consumers who are linked to multiple competitors;

- the interrelations within the cluster itself, often absolutely unpredictable, lead to new ways of competition and bring forth totally new possibilities;

- the human resources and ideas display new combinations.

The most important distinctive feature of the cluster is its innovation-directivity. The most effective clusters usually form in the conditions of the present or forthcoming breakthrough in the sphere of techniques and production technology with further occupation of the new market niches. The transfer from one basic innovation to their integration within one cluster is not a mere formal procedure, but the transition to more qualitative category belonging to macrolevel.

According to M.Porter, clusters may affect the competitiveness in three ways:

- increase of productivity of firms and industrial sectors;

- creation of the opportunities for the innovation and production growth;

- encouragement and facilitation of the new businesses formation processes that would support innovations and cluster's expansion.

Apart from the global statistic indices and the cluster approach to the analysis of the innovation systems there are developed indicators of the international flows of the intellectual capital, but due to the theoretical vagueness of the assessment indices of the advanced technology products only a limited number of the important distinctive features of that flows are fixed. The data that belong to these indices are the information on the technological payments, the global diffusion of patents, the international activity of the research consortiums. The growth of the values of these indices is the sign of the increase of the foreign knowledge flow that could have negative impact on the "national innovative capacity" [6].

The technology balance of payments indicator [3] measures the "know-how" flows (licensing or the sales of patents, trademarks, technological know-hows and intellectual services such as personnel training and R\&D maintenance). This indicator reflects the transfer of technologies and experience that do not mandatorily require the purchase of the machinery and equipment. However, the works on the technological balance of payments guide (as applied to the advanced technology products and services) edited by International Monetary Fund were suspended owing to the mentioned vagueness.

According to the Global Competitiveness Report Survey [7] (24 innovation-related indicators), on the basis of the regressive models it is possible to derive the general innovation index and in addition some thematic subindices (and the ratings of the countries in accordance to them). The viability of the innovations in the economy is estimated via its national innovative capacity.

A similar approach was applied to evaluation of the innovative strength of the national innovation system in the survey OEC NIS based on the OECD information data: Educational Database, Patents Database, Main Science and Technology Indicators, OECD Science, Technology and Industry Scoreboard 2007 [4]. In accordance with this survey the national innovation system can be characterized by the following groups of indicators:

1) "innovation forces": nationwide level investment into the activities correlating to R\&D: private, public, municipal, nationwide expenses on R\&D as a percentage of GDP;

2) national "institutional environment": common macroeconomic conditions, specific stimuli for the innovation activity, the use of information technologies by the constituent subjects of the national innovation system, the quality state of the infrastructure;

3) "knowledge base" as an up-to-date and upcoming outcome of the NIS functioning: the volume of the patents, the researchers' employment rate, the quality performance of the national system of education, the work force quality;

4) "openness", the degree of internationalization of the NIS: the state's international market share of the advanced technology products; international cooperation share in the scientific results; 
5) "terms of financing": the level of development of the national financial markets, the terms of investment (the interest on short and long term credits), the venture capital investment into the science intensive and high technology sectors of industry;

6) "sectorial specificity and specialization": a great number of indicators reflect the scale, innovation result and the competitiveness of the science intensive and high technology sectors of industry.

\section{Results}

Thereby, reasoning from the written above, we acknowledge the fact that there is a tendency to describe the national innovation system with due regard for the indicators of favorable environment for the innovation processes progression and the indices of the intensity of the investment volume into the innovation activity growth. While on the subject of the methods applied to the assessment of the national innovation system the European experience is necessarily worth mentioning: the differential characteristic of European Community consists in irregularity of the economic and sci-tech development of the EU countries, that is practically insuperable in short terms. The European accounts of the innovation activity state in the EU countries, European Innovation Scoreboard (EIS), are annually issued since 2000. During this period the list and the quantity of the EIS indicators-indices have undergone considerable changes. The number of indicators increased from 18 to 29, in particular the number of indicators derived from Community Innovation Survey (CIS) - from 4 to 7. After two fundamental revisions in 2003 and 2005, when nearly $30 \%$ of all the indices were modified, there were only 13 of the indicators common for the earlier surveys left. The list of the countries under examination grew up to 27 , although they differ in the actual presence of their primary data.

EIS indicators are grouped with the view of displaying the key criteria of the innovation process. From the survey we can single out three groups of indicators:

1) the driving force of the innovation (and here there ate three subgroups: human resources, financial resources and the state support);

2) the activity level of the enterprises (includes some subgroups as well: innovation investment cost undertaken by the enterprises, developed intersectorial relations, entrepreneurial ability, the innovation potential level;

3) the production output (it comprises two subgroups: innovation enterprises index and index of the innovation results of innovation).

In spite of the fact that the European system of indicators definitely evolves from year to year, still there are remaining disadvantages in assessment. The major among them is as it was already mentioned the heterogeneity of the economic and sci-tech development of the countries, EU members. For instance, the list of indicators used in calculations does not allow proper assessing the innovation potential of every single country. This can be traced on the example of Norway. If to be guided by the suggested methods of assessment it is fraught with improper conclusion regarding Norway as relatively backward country in the aspect of innovation development, due to its low position in the rating table alongside with Czech Republic, Greece and Spain. But in fact Norway is the world's pre-eminent innovation power in the field of electroenergetics, development of the marine recourses and mining.

\section{Conclusions}

Summarizing all the written above we can conclude that the current innovation policy on the national and world level is mainly carried out in compliance with the narrow definition of the innovation system that emphasizes the innovation approach based on the scientific progress. But for the system perspective the sole condition of attraction of the public and private investment into the R\&D sector is not enough. It is necessary to draw strategic inference from the fact that the organized research works prove to be the main tool in transformation of the innovations into commercial value and that the ability of the firms to take part in such research works vary greatly. Too much attention is paid to the industry that traditionally was science-intensive. The idea that the innovation in the technological sectors of the entry-level (small production, experimental laboratories) stimulates the innovativeness and competitiveness still remains poorly understood in many countries.

\section{References}

Knowledge Economy Index. Direct link: http://info.worldbank.org/etools/ kam2/KAM_page5.asp.

Main Science and Technology Indicators. Direct link: http://www.oecd.org/ sti/msti.htm.

OECD Science, Technology and Industry Scoreboard (biennial publications in 1999-2013). Link: http://www.oecd-ilibrary.org/science- 
and-technology/oecd-science-technology-and-industry-scoreboard_20725345.

Porter M. Competitive Strategy: Techniques for Analyzing Industries and Competitors. - 3d ed. - Moscow: Alpina Business Books, 2007. Glebova, I., Khabibrakhmanova, R., Yasnitskaya, Y. The analysis of the impact of the investment attractiveness factors of the region on the fixed capital investments in the economy of the Republic of Tatarstan // Middle East Journal of Scientific Research 17 (10), pp. 1498-1502,-2014.

Gallyamova D. Kh. Development of Globalization in the Modern Economy // World Applied Sciences Journal 30 (9): 1160-1165, 2014

Rogozhin A.G., Makarenko I.P. The indicators and criteria of monitoring of the innovation systems development processes: the European experience and the lessons for Ukraine. Direct link: http://stepscenter.ho.ua/A08.pdf.

The Global Competitiveness Report // The World Economic Forum Reports. Direct links: http://www3.weforum.org/docs/WEF_Global Competitiveness Report_2013-14.pdf, http://www3.weforum.org/docs/WEF_Global CompetitivenessReport_2014-15.pdf.

Razumovskaya, E.M. , Kutsevol, N., Popov, M., Mishakin, T., Leto, L., Tsalikova, V. The effectiveness of management practice in the market of socially important services, Asian Social Science, Volume 10, 28 September 2014, Pages 118-122

Razumovskaya, E.M., Mishakin, T.S., Popov, M.L., Kucevol, N.G. Medical services during the XXVII world summer universiade 2013 in Kazan. Mediterranean Journal of Social Sciences, Volume 5, Issue 18 SPEC. ISSUE, 2014, Pages 17-20.

Glebova I.S., Yasnitskaya Ya.S., Maklakova N.V. Possibilities of "Smart City" Concept Implementing: Russia' s Cities Practicell Mediterranean Journal of Social Sciences.- Vol.5, No12, (2014)-pp.129 - 133.

Nurieva, A.R., Gibadullin, M.Z., Fazlieva, E.P. Stability of interregional trade and economic relations as the factor of competitiveness of territories, World Applied Sciences Journal, Volume 29, Issue 4, 2014, Pages 501-505 